\title{
Avaliação do ritmo de filtração glomerular
}

\author{
Assessment of glomerular filtration rate
}

Gianna Mastroianni Kirsztajn

\section{abstract}

Glomerular filtration rate (GFR) determination is the most frequently used laboratorial test to evaluate renal function. Indirect markers as blood determination of creatinine and cystatin C are used with this purpose, as well as the direct determination of GFR, with indicators like inulin; iodated contrasts, radioactive or not; and others. Serum creatinine is the test that is most commonly performed in order to evaluate GFR in the clinical pathology laboratory. However, in some conditions, aiming at the adequate interpretation of the test, the result of serum creatinine must be corrected (by using formulas that include individual characteristics of the subjects). In fact, inulin is still seen as the ideal marker of glomerular filtration, but its use is not directed to clinical practice; then the search for appropriate tests for routine use continues.

\begin{tabular}{l|l}
\multicolumn{1}{c|}{ Unitermos } & resumo \\
Ritmo de filtração & A medida do ritmo de filtração glomerular (RFG) é a prova laboratorial mais utilizada na avaliação da \\
glomerular & função renal. Para tanto, usam-se marcadores indiretos, como as determinações de creatinina e cistatina \\
Creatinina sérica & $\begin{array}{l}\text { C no sangue, ou procede-se à determinação do RFG propriamente dito, com indicadores como inulina; } \\
\text { contrastes iodados, marcados ou não; e outras substâncias. O exame mais solicitado para avaliação do RFG } \\
\text { no laboratório de patologia clínica é a dosagem da creatinina sérica. Em algumas condições, entretanto, }\end{array}$ \\
$\begin{array}{l}\text { Depuraçãa de ioexol } \\
\text { o resultado encontrado da creatinina sérica deve ser corrigido (através da utilização de fórmulas que } \\
\text { levam em consideração características próprias do indivíduo) para ser devidamente interpretado. De } \\
\text { fato, a inulina ainda é vista como marcador ideal de filtração glomerular, mas seu uso não se destina à } \\
\text { prática clínica, de modo que ainda hoje persiste a busca por testes adequados para uso rotineiro. }\end{array}$
\end{tabular}

key words

Glomerular filtration rate

Serum creatinine

Cystatin

lohexol clearance

\section{Introdução}

A medida do ritmo de filtração glomerular (RFG) é a prova laboratorial mais utilizada na avaliação da função renal. Para tanto, o teste realizado com maior freqüência no laboratório clínico é a dosagem da creatinina sérica. As funções tubulares são menos comumente avaliadas $^{(29)}$.

Medir adequadamente a função renal é importante não só para fazer o diagnóstico e proceder ao tratamen- to de doenças renais, mas, entre outras aplicações, para administrar doses adequadas de medicações, definir prognóstico, interpretar possíveis sintomas urêmicos e tomar decisão no que se refere a iniciar terapêutica renal substitutiva. Em geral, a avaliação do ritmo de filtração glomerular é vista como o melhor marcador de função renal em indivíduos saudáveis ou doentes(2).

Hoje em dia, considera-se que o RFG pode ser medido de forma precisa utilizando-se marcadores de 
filtração: inulina, iotalamato-l'125, ácido etilenodiaminotetraacético- $\mathrm{Cr}^{51}\left(\mathrm{EDTA}-\mathrm{Cr}^{51}\right)$, ácido dietilenotriaminopenta-acético-Tc ${ }^{99} \mathrm{~m}$ (DTPA-Tc ${ }^{99} \mathrm{~m}$ ) e ioexol ${ }^{(2)}$. No entanto, os testes que os utilizam apresentam algumas desvantagens, entre as quais o custo e a execução trabalhosa, sem levar em conta que alguns envolvem radiatividade, com a conseqüente necessidade de manuseio especial, além do fato de que a disponibilidade desse tipo de marcador é limitada.

Ao longo do texto, teceremos alguns comentários sobre os diferentes marcadores de filtração glomerular disponíveis, enfatizando vantagens e aspectos que limitam o seu uso em nossos dias.

\section{Creatinina}

A dosagem da creatinina, sérica ou plasmática, dá informação sobre o RFG. Esse teste tem a seu favor o fato de ser realizado em todo e qualquer laboratório clínico, com precisão e custo adequados. Os laboratórios freqüentemente lançam mão da reação de Jaffé, que se baseia na formação de um cromógeno, produto da reação da creatinina com picrato, em meio alcalino. Alguns laboratórios mais recentemente têm utilizado também métodos enzimáticos, mais específicos, baseados na hidrólise da creatinina por creatininases. Com quaisquer desses métodos, são necessários volumes reduzidos de amostras; hoje em dia, eles são realizáveis de forma automatizada e relativamente barata, mesmo no caso dos métodos automatizados(27).

Vale salientar, entretanto, que do ponto de vista laboratorial os resultados dessas dosagens são passíveis de interferências e outros problemas, para as quais os clínicos devem estar atentos ${ }^{(32)}$ e que serão discutidos a seguir.

É notório que nem todos os laboratórios utilizam o mesmo método e os valores de referência podem ser diferentes de método para método, de modo que o clínico precisa considerar esse aspecto no acompanhamento de um mesmo paciente, por exemplo, cujas dosagens foram feitas por métodos diferentes. O método de Jaffé sofre interferências bem conhecidas, quais sejam: in vitro, a interferência positiva de cefalosporinas e corpos cetônicos e negativa da bilirrubina. Já os métodos enzimáticos sofrem interferência, in vitro, de $\mathrm{N}$-acetilcisteína e dipirona.

Além dessas considerações referentes a aspectos analíticos do exame, existem características próprias do indivíduo, que podem interferir no resultado final da creatinina. Os valores de referência da creatinina variam com a massa muscular, já que ela é derivada da creatina dos músculos; em conseqüência disso, seus valores são diferentes para crianças, mulheres e homens adultos ${ }^{(29,30)}$.

Vale lembrar que uma das características indispensáveis para que uma substância seja usada como marcador da filtração glomerular é a de que ela seja 100\% filtrada; não seja reabsorvida nem secretada pelos túbulos renais; que sua concentração no meio interno seja mantida constante, só variando em função do ritmo de filtração glomerular do plasma ${ }^{(41)}$. De fato, o ritmo de produção da creatinina é relativamente constante, porém ela tem como inconveniente não ser apenas filtrada, mas também secretada pelos túbulos renais ${ }^{(23)}$.

Alguns autores ${ }^{(2,38)}$ consideram que os níveis séricos de creatinina não são marcadores sensíveis da função renal real em doença renal crônica. Shemesh et al. ${ }^{(38)}$ avaliaram a confiabilidade de marcadores de filtração em doença renal crônica e observaram que era necessária uma redução superior a 50\% na ultrafiltração glomerular antes que ocorresse aumento na creatinina sérica (ou seja, níveis superiores a $1,4 \mathrm{mg} / \mathrm{dl})$. Em outras palavras, muitos indivíduos com doença renal crônica mantêm níveis de creatinina sérica na faixa da normalidade, apesar de terem função renal significantemente diminuída. Essa falha do teste tem sérias implicações quando se pensa em diagnóstico precoce de doença renal crônica, que se faz cada vez mais necessário diante do aumento exponencial da sua freqüência em todo o mundo nos últimos anos ${ }^{(22,24)}$.

As dificuldades mais evidentes no dia-a-dia são encontradas em valores no limite superior, ou próximos, do intervalo de referência, assim como em pacientes portadores de insuficiência renal crônica, indivíduos com perda de massa muscular (paraplégicos, pacientes com miopatias crônicas ou amputados), vegetarianos e idosos.

Alguns dos problemas acima podem ser reduzidos e mesmo eliminados utilizando-se a medida da depuração de creatinina ou equações destinadas à estimativa da depuração de creatinina ou do RFG.

\section{Fórmulas para estimativa do RFG}

O uso de equações desenvolvidas especificamente para a estimativa da depuração de creatinina (Cockcroft-Gault) ou do RFG (MDRD) tem sido defendido por muitos autores ${ }^{(2,21)}$, e alguns chegam a considerar que elas oferecem resultado tão bom quanto ou melhor do que a medida da depuração renal da creatinina. De fato, há inegáveis vantagens no seu uso, mas devemos estar atentos ao fato de que tais equa- 
ções não são aplicáveis a pacientes que se encontrem em situação de instabilidade da função renal, seja por alterações hemodinâmicas, seja por progressão ou recuperação, em prazo de alguns dias, de agravo renal.

Algumas das equações utilizadas para estimar a filtração glomerular são apresentadas a seguir:

\section{1) Cockcroft-Gault}

Depuração de creatinina $=[(140$ - idade $) \times$ peso $] /$ creatinina sérica $\times 72(\times 0,85$ para mulheres)

\section{2) MDRD (fórmula completa)}

RFG $=170 \times$ creatinina sérica ${ }^{-0,999} \times$ idade $^{-0,176} \times$ BUN $^{-0,170}$ $x$ albumina sérica ${ }^{0,318} \times 0,762$ (se mulher) $\times 1,18$ (se afroamericano)

\section{3) MDRD (fórmula simplificada)}

RFG $=186 \times$ creatinina sérica-1,154 $^{-1}$ idade $^{-0,203} \times 0,742$ (se mulher) $\times 1,212$ (se afro-americano)

A segunda fórmula do MDRD é uma versão simplificada, que possibilita o seu uso na prática, já que na fórmula completa há necessidade de utilizar três analitos ao mesmo tempo (dosagens séricas de creatinina, nitrogênio uréico e albumina), o que implica em planejamento prévio para que todos estejam disponíveis e também em maior custo. A fórmula de Cockcroft-Gault estima a depuração de creatinina; é preciso corrigir o resultado obtido com ela para uma superfície corporal de $1,73 \mathrm{~m}^{2}$.

Além disso, não se pode esquecer que a utilização de equações baseadas no nível sérico da creatinina, ou de qualquer outra substância, pressupõe que o método utilizado para a determinação da mesma seja equivalente ao utilizado no serviço que desenvolveu a equação. Caso contrário, correções necessitam ser introduzidas ${ }^{(29,45)}$. Quando se usam as equações do MDRD, recomenda-se a calibração da creatinina nos laboratórios clínicos segundo método de referência, com base em diluição isotópica e espectrometria de massa, e o ajuste da equação do MDRD para tais resultados ${ }^{(2)}$. Esse tipo de cuidado é essencial com vistas à precisão e à comparabilidade dos resultados.

Como mostrado antes, as fórmulas para estimativa da função renal valem-se de equações baseadas em características demográficas (idade, sexo, raça), peso e também em índices bioquímicos, entre os quais destaca-se a creatinina sérica; em uma delas são também usadas a uréia/nitrogênio uréico (BUN) e a albumina. Entre essas fórmulas, provavelmente a mais utilizada é a de Cockcroft e Gault( ${ }^{(5)}$.

Todas as fórmulas aqui apresentadas lançam mão dos níveis séricos da creatinina, sofrendo, portanto, a influência desse indicador. Esse aspecto é deveras importante, posto que, como enfatizado anteriormente, a creatinina é um marcador de filtração que não é sensível a diminuições leves ou moderadas no RFG ${ }^{(2)}$, com suas conseqüências sobre os resultados obtidos com as fórmulas.

Bostom et al. ${ }^{(2)}$ realizaram interessante estudo para avaliar a capacidade preditiva de determinadas equações para pacientes com doença renal crônica e níveis séricos de creatinina dentro da faixa de normalidade. Eles compararam os resultados de oito equações preditivas em 109 pacientes com doença renal crônica e níveis séricos de creatinina inferiores ou iguais a $1,5 \mathrm{mg} / \mathrm{dl}$ com os valores de RFG determinados com o uso de ioexol. Mesmo os resultados mais acurados apresentaram níveis de erro que os tornaram subótimos para o tratamento clínico desses pacientes. Os resultados sugerem que a medida do RFG com marcadores de filtração endógena ou exógena deve ser a estratégia mais prudente para avaliação da função renal na população de pacientes com doença renal crônica (cujo diagnóstico foi estabelecido por outros critérios) com níveis séricos de creatinina normal.

\section{Cistatina C}

Cabem aqui alguns comentários sobre a cistatina $C$ como marcador indireto de filtração glomerular que vem ganhando grande aceitação mundial ${ }^{(16,26,40,46)}$.

As cistatinas em geral, e entre elas a cistatina $C$, aqui em destaque, constituem uma superfamília de proteínas. Seus membros são, na maioria, inibidores de proteases cisteínicas. Essas proteases desempenham papel importante no catabolismo intracelular de peptídeos e proteínas, no processamento de pró-hormônios e no metabolismo do colágeno; além disso, parecem interferir no processo de invasão de tecidos normais por microorganismos ou células tumorais.

Até o momento foram descritas pelo menos três famílias de cistatinas: família 1, com cistatinas A e B; família 2, com cistatinas $C, D, E / M, F, S, S N$ e AS; e família 3, com os cininogênios de alto e baixo peso molecular. É possível que novos membros venham a ser adicionados a essas famílias ${ }^{(4)}$.

A cistatina $C$ tem 120 aminoácidos, peso molecular de 13.359 dáltons e é bastante estável em amostras de soro ou plasma. Amostras desses líquidos podem ser armazenadas 
em geladeira ou congeladas por semanas ou meses, sem qualquer degradação. Curiosamente, essa estabilidade não é observada em amostras de liquor ou de urina.

A cistatina $C$ é produzida em ritmo constante por células nucleadas, e seu nível plasmático parece não sofrer variações por causas extra-renais, o que a caracteriza como marcador adequado de ritmo de filtração glomerular. Seu ritmo de síntese não parece ser alterado por coexistência de processos inflamatórios e é razoavelmente constante ${ }^{(25)}$.

A cistatina é eliminada do plasma por filtração glomerular. Nos glomérulos, seu coeficiente de filtração está próximo de 1 , sendo quase que totalmente reabsorvida e catabolizada nos túbulos contornados proximais, como ocorre com outras proteínas de baixo peso molecular ${ }^{(8,15,19,26,28,44)}$. É passível de ser determinada imunoquimicamente. Seu nível sérico não difere de forma expressiva entre crianças, mulheres e homens adultos; por isso, tem sido indicada como um possível substituto para a creatinina como marcador do RFG. A sua concentração não é dependente da idade ${ }^{(7)}$.

Vários autores defendem que ela seria mais sensivel do que a creatinina sérica para a detecção precoce de insuficiência renal; outros, contudo, pensam que essa aparente vantagem desaparece quando se usa uma das equações, já mencionadas, que envolvem a creatinina. Deve ficar claro que esses pesquisadores defendem o uso das fórmulas e não a dosagem sangüínea da creatinina isoladamente, considerando que ela não deve ser usada sem se levarem em conta a massa muscular, o gênero ou a idade do indivíduo ${ }^{(1,25,40)}$.

Equações para estimar o RFG baseadas na concentração sérica de cistatina $C$ também têm sido propostas e carecem de avaliação em diferentes centros ${ }^{(16)}$. Num deles, os autores inicialmente demonstraram a existência de correlação significativa e mais forte entre os níveis de cistatina $\mathrm{C}$ e o clearance de ioexol do que entre este e os níveis de creatinina sérica. A partir daí, criaram uma fórmula para converter cistatina C (expressa em $\mathrm{mg} / \mathrm{l}$ ) em RFG (em $\mathrm{ml} / \mathrm{min}$ ) e ambos os resultados passaram a ser encaminhados para os médicos que solicitavam a dosagem de cistatina ${ }^{(20)}$.

Alguns pesquisadores que analisaram a questão da reprodutibilidade da determinação da cistatina $\mathrm{C}$ concluíram que ela pode ser determinada com alta precisão, tão boa quanto ou melhor do que a conseguida nos métodos para determinação de creatinina ${ }^{(19)}$, aspecto que é extremamente importante em avaliações funcionais.

Ainda não existem publicações suficientes sobre a utilidade da cistatina $C$ sérica em algumas condições, es- pecialmente no contexto da doença renal crônica; sendo assim, consideramos que é preciso levar em conta as reais aplicações da cistatina $C$ e utilizá-la na prática diária apenas nas situações em que sua dosagem de fato implique em ganho para o paciente.

Obviamente, existem outros marcadores endógenos, além da creatinina e da cistatina $C$, que possibilitariam a medida indireta do RFG; não acreditamos, entretanto, que uma revisão extensa sobre cada um deles possa ser útil. Já se considerou, por exemplo, a possibilidade de usar a beta 2-microglobulina sérica para esse fim. Sua concentração sérica é independente da massa muscular e do gênero do indivíduo, mas seus níveis se elevam sabidamente em caso de doenças inflamatórias e linfoproliferativas, o que limitou sobremaneira a sua aplicação nesse contexto.

A dosagem da uréia, por sua vez, é usada tradicionalmente para verificação da função renal e é um teste facilmente disponível; todavia, é preciso ter em mente que sua precisão é baixa quando se destina à avaliação do RFG, uma vez que não tem ritmo de produção estável, sofre reabsorção tubular, e seu nível sérico é altamente dependente da alimentação do indivíduo e do catabolismo protéico.

\section{Depuração de diferentes marcadores do RFG}

\section{Inulina}

A inulina é um polímero da frutose, cujo peso molecular é de 5.200 dáltons. Exceto por ser um marcador exógeno, preenche os demais critérios que um marcador ideal de filtração glomerular deveria ter. Por outro lado, complicando o seu uso na rotina de avaliação de função renal, citam-se dificuldades para a realização do exame propriamente dito, tais como: padronização estrita do método, infusão endovenosa contínua do marcador, dosagem laboratorial complexa e trabalhosa e alto custo; além disso, existe a possibilidade de que determine reações de hipersensibilidade.

Apesar de tudo isso, ainda hoje se considera que o padrão-ouro para medida do RFG é a determinação do ritmo de depuração renal da inulina. Mas a viabilidade de aplicá-la a pacientes, seja em rotina de atendimento, seja em estudos clínicos, é extremamente limitada ante sua difícil obtenção, particularmente quando se fala de inulina apropriada para infusão em humanos; além das dificuldades já referidas anteriormente. Mais recentemente, tem-se dado preferência ao uso de quelatos marcados, como o $\mathrm{Cr}^{56}$-EDTA; $\mathrm{Tc}^{99 \mathrm{~m}}$-DTPA; ou contrastes iodados, radiativos 
(como no caso do l'25-iotalamato) ou não (como o próprio iotalamato ou o ioexol) $)^{(9,18)}$.

\section{Depuração de substâncias radiativas}

Quando a substância utilizada é radiativa, existe a necessidade de uma licença especial para o seu manuseio expedida por órgãos reguladores, o que só ocorre após credenciamento do usuário. Além disso, é preciso ter em mente a questão da exposição de paciente e pessoal técnico, assim como do destino do lixo radiativo.

A depuração do $\mathrm{Cr}^{51}$-EDTA e a do TC ${ }^{99 m}$-DTPA, consideradas seguras, são os métodos que envolvem isótopos radiativos mais usados para medida do RFG. Ao longo dos anos, esses métodos têm passado por um processo de simplificação, com determinação do menor número de amostras necessárias para a adequada construção da curva de decaimento do marcador no plasma ${ }^{(31)}$.

A determinação do RFG por Cr $^{51}$-EDTA apresenta grau elevado de correlação com a de inulina. Existem vários estudos a respeito, inclusive explorando a reprodutibilidade da técnica com vários tempos e diferentes números de coleta de sangue $(29,30,32)$.

\section{loexol e iotalamato}

No caso dos contrastes radiológicos não-radiativos, as determinações têm sido feitas por cromatografia líquida de alta performance (HPLC), por fluorescência, após irradiação com raios $X$, ou por eletroforese capilar ${ }^{(29,30)}$.

Quando usados para determinação do RFG, os contrastes radiológicos podem ser aplicados pela técnica da injeção única ou, menos freqüentemente, da infusão contínua. Pode ser medido o ritmo de desaparecimento da substância do plasma, após injeção endovenosa, ou o ritmo de depuração renal, que implica na coleta de períodos de diurese, cronometrados $(3,6,9,18,34,39,42)$. Esse tipo de exame exige coletas de várias amostras de sangue, é de duração prolongada e de custo elevado.

O iotalamato (contraste iônico) e o ioexol (contraste não-iônico) são ambos livremente filtrados pelos glomérulos. Não sofrem reabsorção nem secreção. São muito precisos e apresentam alto coeficiente de correlação com a inulina ${ }^{(10,11)}$.

Existe a possibilidade de que ocorra alergia ao contraste iodado, de modo que é importante questionar o paciente sobre eventos prévios dessa natureza e contar, no local de exame ou proximidades, com recursos para prestar cuidados médicos diante de uma eventual reação alérgica.

\section{Discussão}

Para médicos em geral, patologistas clínicos e sobretudo nefrologistas, é grande a preocupação com a determinação da real função renal, visto que com certa freqüência eles precisam definir se um certo indivíduo tem ou não filtração glomerular normal diante do achado casual de um sedimento urinário anormal, de proteinúria isolada ou de uma alteração anatômica em exame de imagem. Não é incomum que esses pacientes apresentem níveis séricos de creatinina na faixa da normalidade, por motivos amplamente discutidos neste artigo. Em situações como essas ou simplesmente quando se procede a um check-up e é preciso estabelecer a situação da função renal do indivíduo, não existe realmente um exame simples, prático, sensível, de baixo custo e de realização rápida que permita ao médico ter a certeza de que seu paciente de fato tem função renal normal.

Devido à imprecisão observada, em algumas situações, na utilização de marcadores de filtração glomerular, como a creatinina sérica, é defendido atualmente, em todo o mundo, o uso de fórmulas para estimativa do RFG. As diferentes fórmulas, além de incluírem a concentração sérica de creatinina, utilizam fatores de correção, como sexo, idade, raça, entre outros, possibilitando maior individualização do resultado e sensibilização do teste com o objetivo de detectar déficit de função renal(1, 12-14, 17, 21, 33, 35, 36).

A preocupação com a avaliação do RFG é antiga, mas o interesse por essa discussão ressurgiu diante do crescimento exponencial da população portadora de doença renal crônica em todo o mundo(22). Essa situação exige avaliação precisa de RFG, diagnóstico precoce de doença e tomada ágil de atitude em face das alterações funcionais evidenciadas. Além disso, é preciso fazer todo um trabalho de diagnóstico populacional dessas doenças; há a necessidade de definir os melhores testes de triagem e a forma adequada de interpretá-los, assim como de estabelecer sua população-alvo.

Adicionalmente, diferenças no que tange à composição das populações, em particular a questão racial, ainda não foram suficientemente estudadas em relação às suas implicações sobre marcadores de função renal e fórmulas que levam em conta correções para raça. É o caso da fórmula do MDRD, que acrescenta um fator de correção quando se trata de indivíduo de origem afro-americana dos EUA, criada com base em um grupo populacional específico e 
que pode não encontrar paralelo na população brasileira e em muitas outras.

Continua, pois, a busca por um marcador ideal do ritmo de filtração glomerular, uma substância que possa ser determinada rapidamente, de forma não dispendiosa, que não sofra influência de fatores extra-renais, não exija administração exógena, não varie com a idade, nem com a composição corporal|(43).

Marcadores precisos até existem, mas em geral são de difícil uso, trabalhosos e pouco práticos no dia-a-dia. A cistatina $C$ é um marcador que vem ganhando grande aceitação mundial, apesar de ainda não se mostrar adequado para uso nas avaliações de função renal de rotina, devendo ser também respeitadas as suas limitações; deve ser solicitada apenas nas situações em que de fato sua utilidade foi testada, em que as pesquisas mostraram sua real contribuição.

No dia-a-dia da prática clínica, quando, além das características técnicas do método diagnóstico em uso, é fundamental atentar para aspectos como tempo para se ter o resultado do teste e sobretudo o custo do mesmo, a dosagem da creatinina sérica continua a ser de grande utilidade mundialmente ${ }^{(31)}$. Portanto, a creatinina tem seu valor como marcador de função renal e não deve ser abandonada. É preciso saber usar a creatinina sérica e sensibilizar o seu resultado através da aplicação de fórmulas para avaliação do RFG.

Por fim, não são raras as circunstâncias em que uma medida mais representativa do estado funcional renal se torna necessária; por isso, pesquisar novos marcadores de maior aplicabilidade clínica e testar os que se encontram disponíveis são desafios aos quais não podemos nos furtar.

\section{Conclusões}

Métodos que usam inulina, contrastes iodados ou substâncias radiativas, embora já padronizados, não são corriqueiramente utilizados na prática clínica. Portanto, na definição diária da conduta ante pacientes com nefropatias ou mesmo para o grande contingente de indivíduos em que se deseja afastar a existência de nefropatia, especialmente incipiente, ainda não existem indicadores adequados para triagem que sejam precisos, sensíveis e poucos invasivos. Por outro lado, se eles existem, ainda não se comprovou de maneira convincente sua real aplicabilidade nessas situações e o quanto eles acrescentam em relação aos marcadores já em uso.

Por fim, ainda se faz necessário combinar marcadores de função renal lato sensu para agir com maior tranqüilidade diante de cada caso a ser esclarecido. Determinações de proteinúria e/ou microalbuminúria têm papel relevante nesse contexto. No que diz respeito à avaliação de filtração glomerular propriamente dita, o uso de fórmulas com o fim de sensibilizar o resultado da creatinina sérica, a dosagem da cistatina $C$ sérica e a medida da depuração de marcadores iodados e/ou radiativos são todos recursos com que podemos contar, cada um com maior ou menor indicação em situações específicas.

\section{Agradecimentos}

Agradeço ao apoio financeiro da Fundação de Amparo à Pesquisa do Estado de São Paulo (FAPESP) e do Conselho Nacional de Desenvolvimento Científico e Tecnológico (CNPq), que têm possibilitado o desenvolvimento de estudos envolvendo marcadores de função renal no Setor de Glomerulopatias da UNIFESP.

Faço um agradecimento especial ao Professor-doutor Aparecido B. Pereira, expert na área de avaliação de função renal, cuja dedicação ao tema possibilitou que muitos de seus orientandos e leitores se interessassem pela realização de estudos em busca de marcadores adequados de filtração glomerular e/ou de sua aplicabilidade na população brasileira.

\section{Referências}

1. BÖKENKAMP, A. et al. Cystatin C: a new marker of glomerular filtration rate in children independent of age and height. Pediatrics, v. 101, n. 5, p. 875-81, 1998.

2. BOstom, A.G.; KRONENBERG, F.; RITZ, E. Predictive performance of renal function equations for patients with chronic kidney disease and normal serum creatinine levels. J Am Soc Nephrol, v. 13, p. 2140-4, 2002.

3. BROWN, S.C.W.; O'REILLY, P. The estimate of glomerular filtration rate during urography. Acceptability of a nonionic contrast medium as a marker of renal function. Invest Radiol, v. 27, n. 10, p. 774-8, 1992. 
4. BROWN, W.M.; DZIEGIELEWSKA, K.M. Friends and relations of the cystatin superfamily: new members and their evolution. Protein Sci, v. 6, p. 5-12, 1997.

5. COCKCROFT, D.W.; GAULT, M.H. Prediction of creatinine clearance from serum creatinine. Nephron, v. 16, p. 31-41, 1976.

6. ERIKSSON, C.G.; KALLNER, A. Glomerular filtration rate. A comparison between Cr-EDTA clearance and a single sample technique with a non-ionic contrast agent. Clin Biochem, v. 24, p. 261-4, 1991.

7. FILLER, G. et al. Are cystatin C and B2-microglobulin better markers than serum creatinine for prediction of a normal glomerular filtration rate in pediatric subjects? Clin Chem, v. 43, n. 6, p. 1077-8, 1997.

8. FINNEY, $\mathrm{H}$. et al. Initial evaluation of cystatin $\mathrm{C}$ measurement by particle-enhanced immunonephelometry on the Behring nephelometer systems (BNA, BN II). Clin Chem, v. 43, n. 6, p. 1016-22, 1997.

9. FRENNBY, B. et al. The use of iohexol clearance to determine GFR in patients with severe chronic renal failure: a comparison between different clearance techniques. Clin Nephrol, v. 43, n. 1, p. 35-46, 1995.

10. GASPARI, F.; PERICO, N.; REMUZZI, G. Application of newer clearance techniques for the determination of glomerular filtration rate. Curr Opin Nephrol Hypertens, v. 7, p. 675-80, 1998.

11. GASPARI, F. et al. Plasma clearance of nonradioactive iohexol as a measure of glomerular filtration rate. J Am Soc Nephrol, v. 6, n. 2, p. 257-63, 1995.

12. GATES, G.F. Creatinine clearance estimation from serum creatinine values: an analysis of three mathematical models of glomerular function. Am J Kidney Dis, v. 5, p. 199-205, 1985.

13. GAULT, M.H. et al. Predicting glomerular function from adjusted serum creatinine. Nephron, v. 62, p. 249-56, 1992.

14. GOLDBERG, T.H., FINKELSTEIN, M.S. Difficulties in estimating glomerular filtration rate in the elderly. Arch Intern Med, v. 147, p. 1430-3, 1987.

15. GRUBB, A. Diagnostic value of analysis of cystatin $C$ and protein HC in biological fluids. Clin Nephrol, v. 38, n. 1, p. S20-S7, 1992.

16. GRUBB, A. et al. Simple cystatin C-based equations for glomerular filtration rate compared with the modification of diet in renal disease prediction equation for adults and the Schwartz and Counahan-Barratt prediction equations for children. Clin Chem, n. 51, p. 1420-31, 2005.

17. JELLIFFE, R.W.; JELLIFFE, S.M. A computer program for estimation of creatinine clearance from unstable serum creatinine levels, age, sex, and weight. Math Biosc, v. 14, p. 17-24, 1972.

18. KRUTZÉN, E. et al. Plasma clearance of a new contrast agent iohexol: a method for the assessment of glomerular filtration rate. J Lab Clin Med, v. 104, n. 6, p. 955-61, 1984.

19. KYHSE-ANDERSEN J. et al. Serum cystatin C detemined by a rapid, automated particle-enhanced turbidimetric method is a better marker than serum creatinine for glomerular filtration rate. Clin Chem, v. 40, n. 10, p. 1921-6, 1994
20. LARSSON, A. et al. Calculation of glomerular filtration rate expressed in $\mathrm{mL} / \mathrm{min}$ from plasma cystatin $\mathrm{C}$ values in mg/L. Scand J Clin Lab Invest, v. 64, n. 1, p. 25-30, 2004.

21. LEVEY A.S. et al. A more accurate method to estimate glomerular filtration rate from serum creatinine: a new prediction equation. Ann Intern Med, v. 130, p. 461-70, 1999.

22. MASTROIANNI KIRSZTAJN, G. Prevenção de doença renal: uma preocupação crescente. Medicina on Line, maio de 2006. Disponível em: http://www.medonline. com.br/gianna.html. Acesso em: 8 jun. 2007.

23. MONTEIRO, M.C.A. et al. Assessment of glomerular filtration rate utilizing subcutaneously injected $51 \mathrm{Cr}$ EDTA. Brazilian J Med Biol Res, v. 27, p. 2557-64, 1994.

24. MONTEIRO, S.R.; MASTROIANNI KIRSZTAJN, G. Introdução do clearance estimado de creatinina na rotina de um laboratório. J Bras Nefrol, v. 28, n. 2, p. S25-S7, 2006.

25. MYERS, G.L. et al. Recommendations for improving serum creatinine measurement: a report from the Laboratory Working Group of the National Kidney Disease Education Program. Clin Chem, v. 52, p. 5-18, 2006.

26. NEWMAN, D.J. et al. Serum cystatin $C$ measured by automated immunoassay: a more sensitive marker of changes in GFR than serum creatinine. Kidney Int, v. 47, p. 312-8, 1995.

27. NEWMAN, D.J.; PRICE, C.P. In: BURTIS, C.A.; ASHWOOD, E.R. (eds). Tietz textbook of clinical chemistry. $3^{\text {rd }}$ ed. Philadelphia: W.B. Saunders Co., 1999. p. 1243.

28. NILSSON-EHELE, P.; GRUBB, A. New markers for the determination of GFR: iohexol clearance and cystatin C serum concentration. Kidney Int, v. 46, suppl. 47, p. 17-9, 1994.

29. PEREIRA, A. B.; NISHIDA, S.K.; MASTROIANNI KIRSZTAJN, G. Como avaliar o ritmo de filtração glomerular. J Bras Nefrol, v. 28, n. 2, p. S15-S8, 2006.

30. PEREIRA, A.B.; NISHIDA, S.K.; SILVA, M.S. A situação atual da avaliação da função renal. In: CRUZ, J. et al. Atualidades em Nefrologia 9. São Paulo: Sarvier, 2006. p. 91-8.

31. PERRONE, R.D. et al. Utility of radioisotopic filtration markers in chronic renal insufficiency: simultaneous comparison of 125I-iothalamte, 169Yb-DTPA, 99TcDTPA and inulin. Am J Kidney Dis, v. 16, p. 224-35, 1990.

32. PERRONE, R.D.; MADIAS, N.E.; LEVEY, A.S. Serum creatinine as an index of renal function: new insights into old concepts. Clin Chem, v. 38, p. 1933-53, 1992.

33. PIERRAT, A. et al. Predicting GFR in children and adults: a comparison of the Cockcroft-Gault, Schwartz and modification of diet in renal disease formulas. Kidney Int, v. 64, p. 1425-36, 2003

34. RocCO, M.V. et al. Capillary electrophoresis for the determination of glomerular filtration rate using nonradioactive iohexol. Am J Kidney Dis, v. 28, n. 2, p. 173-7, 1996.

35. SCHWARTZ, G.J. et al. A simple estimate of glomerular 
filtration rate in children derived from body length and plasma creatinine. Pediatrics, v. 58, p. 259-63, 1976.

36. SCHWARTZ, G.J.; GAUTHIER, B. A simple estimate of glomerular filtration rate in adolescent boys. J Pediatr, v. 106, p. 522-6, 1985.

37. SCHWARTZ, G.J.; BRION, L.P.; SPITZER, A. The use of plasma creatinine concentration for estimating glomerular filtration rate in infants, children, and adolescents. Pediatr Clin North Am, v. 34, p. 571-90, 1987.

38. SHEMESH, O. et al. Limitations of creatinine as a filtration marker in glomerulopathic patients. Kidney Int, v. 28, p. 830-8, 1985.

39. SHIHABI, Z.K.; CONSTANTINESCU, M.S. lohexol in serum determined by capillary electrophoresis. Clin Chem, v. 38, n. 10, p. 2117-20, 1992.

40. SIMONSEN, O; GRUBB, A; THYSELL, H. The blood serum concentration of cystatin $C$ (gamma trace) as a measure of the glomerular filtration rate. Scand J Clin Lab Invest, v. 45, p. 97-101, 1985.
41. SMITH, H.W. The kidney: structure and function in health and disease. New York: Oxford University Press, 1951.

42. STAKE, G. et al. The clearance of iohexol as a measure of the glomerular filtration rate in children with chronic renal failure. Scand J Clin Lab Invest, v. 51, p. 729-34, 1991.

43. SWAN, S.K. The search continues: an ideal marker of GRF. Clin Chem, v. 43, n. 6, p. 913-4, 1997.

44. TIAN, S. et al. Cystatin $C$ measurement and its practical use in patients with various renal diseases. Clin Nephrol, v. 48, n. 2, p. 104-8, 1997.

45. VAN BIESEN, W. et al. The importance of standardization of creatinine in the implementation of guidelines and recommendations for CKD: implications for CKD management programmes. Nephrol Dial Transplant, v. 21, n. 1, p. 77-83, 2006.

46. VAN ROSSUM, L.K. et al. Renal extraction of cystatin C vs 125 I-iothalamate in hypertensive patients. Nephrol Dial Transplant, v. 21, p. 1253-6, 2006. 